\title{
A Contribution to Guide the Use of Support Tools for Technology Roadmapping: a Case Study in the Clothing industry
}

\author{
Cindy J. Ibarra G.',André Ogliari²,Aline F. de Abreu
}

\begin{abstract}
This article presents guidelines regarding the use of tools to support technology roadmapping based on a case study of an exploratory and descriptive nature in a small company in the clothing sector. After introducing a systematic approach to technology roadmapping with their support tools, an empirical analysis is then presented of the application of the tools of the market layer - a questionnaire for consultation with the consumers and bibliographical research - and the business layer - SWOT matrix, through illustrative examples. Each tool was analyzed in relation to the complexity, time, cost of implementation, relevance and quality of the resulting information, the most common problems associated with their use. Here we show that the tools of the market layer proved to be easiest to use when compared with the tools of business layer, varying the time required, but involving, in general, a low cost in its application to obtain relevant and quality results for the development of the roadmap. Based on the results, general guidelines for the use of these tools to assist in the process of technology roadmapping were established as well as a comparison between the tools.
\end{abstract}

Keywords: roadmapping tools; market analysis; business strategic planning.

\footnotetext{
1,2Center for Integrated Product Development (NeDIP), Department of Mechanical Engineering. Email: cjibarra03@hotmail.com ${ }^{3}$ Center for Studies in Innovation, Management and Information Technology (IGTI), Department of Production Engineering and Systems. Federal University of Santa Catarina, R. Eng. Agronômo Andrey Cristian Ferreira, Trindade, 88040-900, Florianópolis, SC, Brazil.
} 


\section{Introduction}

In the current technological and market environment, companies need to anticipate and rapidly respond to changes to maintain their competitive position. According to Coral, Ogliari and Abreu (2008), there is nothing new in monitoring the movements of competition and the market, but to succeed, it is necessary to systematize this activity, treating it as a continuous process and seeking to incorporate the information into the decision-making process. Although the systematization of information may seem a simple task in theory, in practice requires considerable effort related to the survey, prioritization, assessment and organization of information to support the decision making. One method that meets these requirements is technology roadmapping. For its implementation support tools are used and so it is necessary to understand how these tools work to ascertain the quality of the information obtained and to evaluate whether or no they are simple, fast and cheap to use in order to make their application in companies feasible.

In this context, the objective of this article is to present an analysis of the use of support tools for the technology roadmapping process through an exploratory and descriptive case study in a small company in the clothing sector. The intention is to show how the tools behave and contribute to the implementation of the method. The tools analyzed relate to the market layer - a questionnaire for consultation with the consumers and bibliographical research - and the business layer - SWOT matrix, an acronym for Strengths, Weaknesses, Opportunities and Threats.

First, a systematic approach to technology roadmapping is presented, detailing the market and business layers and their respective support tools. The research methodology used is then described. The application of the layers of market and business tools is demonstrated to assist in the systematization of information in a company of the clothing sector motivated by the internationalization of its products. By means of examples, the procedure followed in the survey and processing of the relevant information for the development of the roadmap is illustrated, where it was possible to contextualize the current situation in the target market and forecast future potential opportunities to formulate strategic actions for a better competitive position of the company. Finally, each tool is analyzed empirically through observation and experience in relation to the attendance (low, medium or high) of the criteria of the complexity, time and cost of implementation as well as the relevance and quality of the resulting information, which are crucial to the implementation of the method as observed in previous experiences.

\section{Systematic approach to Technology Roadmapping}

According to Albright and Kappel (2003), technology roadmapping is a method that aims to assist in the planning of the evolution and integration of market, product and technology strategies as part of the business. Since its conception in the $80 \mathrm{~s}$, the method has been used for different purposes in various industrial sectors due to its flexible structure. These industrial sectors include electronics (Motorola - Richey and Grinnell, 2004; Philips Electronics - Groenveld, 1997), pharmaceutical-biotechnology (McCarthy, 2003), industrial automation (McMillan, 2003), automotive (General Motors - Grossman, 2004), telecommunications (Lucent Technologies - Albright and Kappel, 2003), and software development (Phaal, Farrukh and Probert, 200I). In the literature no applications of the method specifically to the clothing sector could be found. Figure I shows the Systematization of Technology RoadMapping (SyTRM) developed to guide step by step the development of the roadmap and facilitate the planning of new products and technologies in companies.

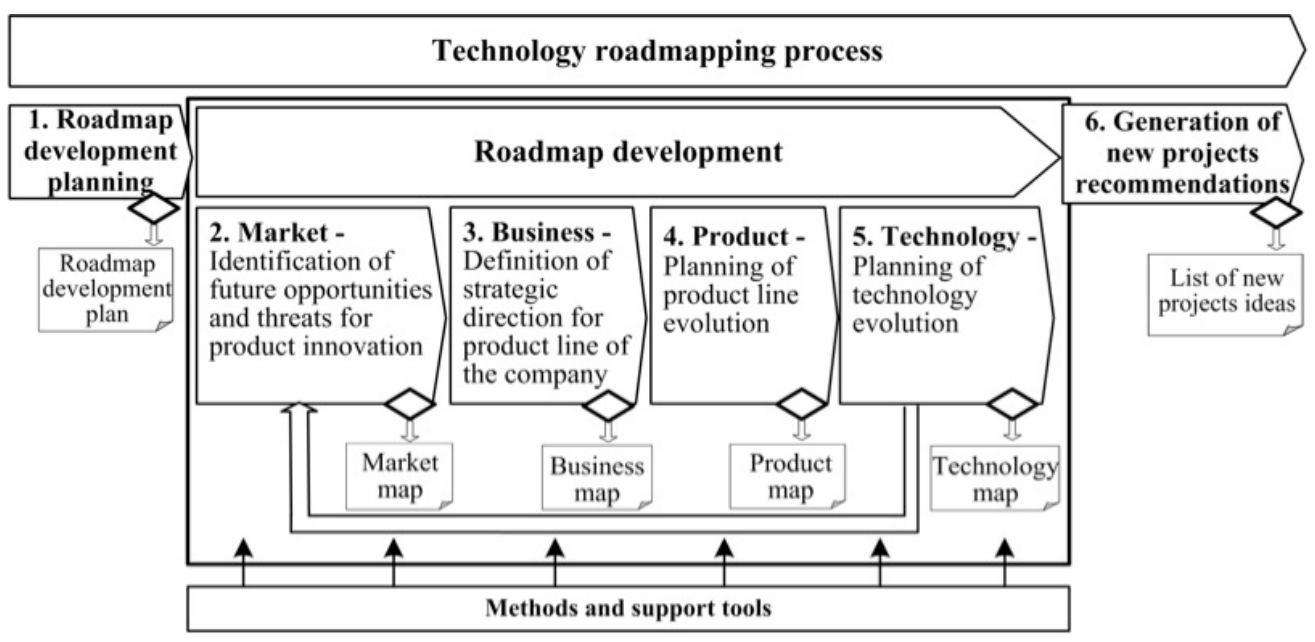

Figure I. Snapshot of the Systematization of the Technology Roadmapping (SyTRM) (Ibarra, 2007 and Ibarra, Ogliari and Back, 2009).

ISSN: 07I 8-2724. (http://www.jotmi.org)

Journal of Technology Management \& Innovation @ Universidad Alberto Hurtado, Facultad de Economía y Negocios. 
The systematic proposal (SyTRM) is composed of three macrophases:

- Roadmap development planning: which aims to guide the definition of the product line to be analyzed, time scale, participants, schedule and budget, which, in turn, will guide the development of the technology roadmap;

- Roadmap development - this macrophase is composed of four phases: identification of future opportunities and threats for product innovation, definition of strategic direction for product line of the company, planning of product line and technology evolution. The results of the implementation of these phases correspond to the goals of the layers of the roadmap. Although described sequentially to provide a systematic approach, this macrophase is, by nature, iterative and continuous, and as the company learns more about its environment, its own capabilities and how to develop them with success over time the roadmap is filled out with more information, the fruits of the discussions and interactions among the members of the team; and,

- Generation of new project recommendations: this macrophase leads to a summary of the main results obtained during the process of technology roadmapping in the form of new development projects of high priority that must be undertaken to achieve the objectives of the company.

The general structure of the resulting roadmap, with the characterization of each layer is shown in Figure 2.
The market layer is related to the monitoring of the competitive environment of the company, in terms of market trends, changes and social, environmental, political, economic and technological developments, which configures opportunities "external" to the company innovate. The business layer is linked to the planning of strategic targets "internal" to the company. These two layers constitute the motivation (the "why") which drives the development of new products. The information required is of a strategic nature, characterized by long-term estimates, in which decisions are taken in relation to the external changes that the company has to do make in order to contribute to the business strategy. In the product and technology layers the internal changes necessary to achieve the strategy are planned, i.e. the new products (the "what") and the technologies and capabilities (the "how") to be developed by the company. The central layer, the product layer on the roadmap constitutes the bridge between the external and internal opportunities of the company. Internal opportunities arise from the use of internal research, new capabilities and skills developed by the company. This information is considered to be of an innovative character and, its planning is generally in the medium-term. Thus, the roadmap can be interpreted and used by the company in two directions: top-down and bottom-up.

In this article, the tools of phase 2 and 3 used in the identification of future opportunities and threats for product innovation and the definition of the strategic direction for line product of the company (Figure I) will be analyzed in greater detail, and the resulting information is positioned in the market and business layers respectively (Figure 2).

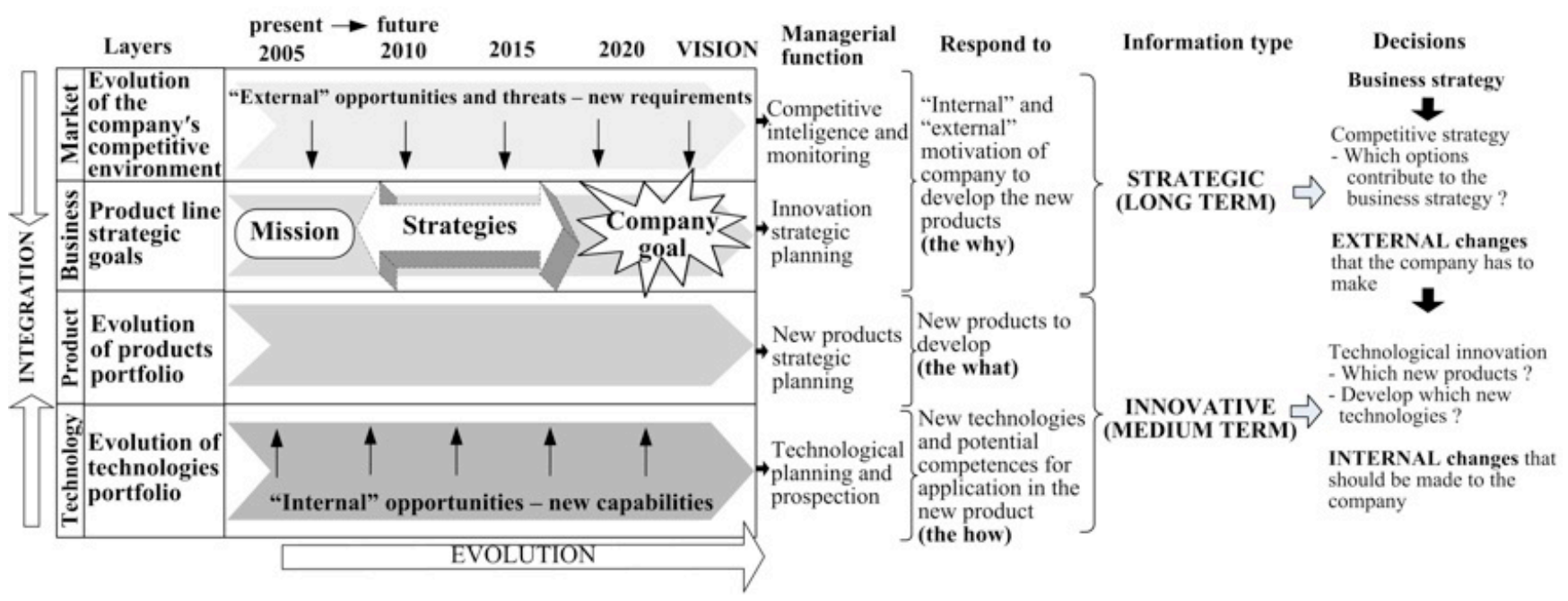

Figure 2. Basic structure of the technology roadmap and its layers (lbarra, 2007)

ISSN: 07I 8-2724. (http://www.jotmi.org)

Journal of Technology Management \& Innovation @ Universidad Alberto Hurtado, Facultad de Economía y Negocios. 


\section{Identification of future opportunities and threats for product innovation: market layer}

The objective of this phase is to identify how the organization should guide its strategies to meet the future needs of the product. Figure 3 shows the flow of the activities proposed for this phase.

In the first activity (2.I) the priorities of customers in the purchase of the product (qualitative aspects) and the potential market (quantitative aspects) which can be obtained by means of projections of the product market, analyzing the size and market share and expected growth (lbarra, Ogliari and Back, 2008) are identified. The survey of the qualitative information can be performed using as tools: the questionnaire structured for consultation with the consumers and bibliographical research, whose procedures are illustrated in Figure 4.
The questionnaire (a) is an instrument of data collection, consisting of an ordered series of questions, which must be answered in writing and without the presence of the researcher (Marconi and Lakatos, 2006). It is aimed at gaining knowledge regarding the respondents' opinions, beliefs, feelings, interests, expectations, situations experienced, etc. When the questions are asked orally by the researcher they may be designated as questionnaires applied with an interview or forms (GIL, 2006).

The application of a questionnaire involves: (I) the planning of desired future results in terms of the problem to be investigated, the objectives, the target audience and the strategies for the subsequent actions considering deadlines and required resources. For Labes (1998), it is by means of the planning that the researcher can anticipate the difficulties and barriers that often compromise the efficacy and validity of a research study; and (2) in the preparation of

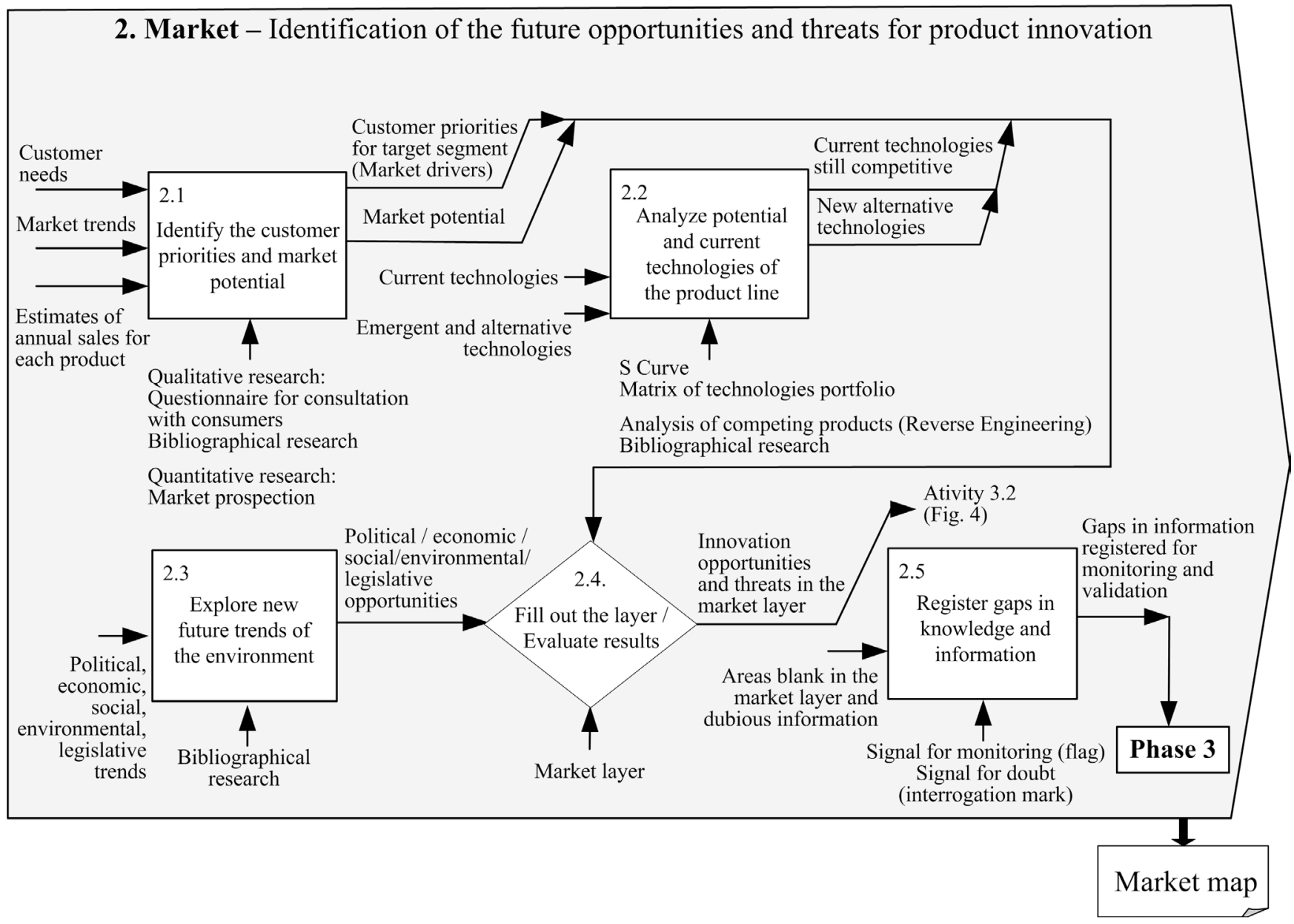

Figure 3. Flow of activities of identification of the future opportunities and threats for product innovation (adapted from Ibarra, Ogliari and Back, 2008)

ISSN: 07I 8-2724. (http://www.jotmi.org)

Journal of Technology Management \& Innovation (C) Universidad Alberto Hurtado, Facultad de Economía y Negocios. 
the questionnaire the observance of several factors is required as described by Marconi and Lakatos (2009), in order to increase the efficacy and validity of the research. These are: the type of questions in a language accessible or common to the target audience, the order of presentation, the grouping of questions by matters, and the clear, objective and concise formulation of the questions so that they can be easily understood. For the appropriate elaboration of questions, which can be opened, closed or multiple-choice, Brace (2004), Boynton and Greenhalg (2004) and Gil (2006) present a series of guidelines that can be followed.

According to Labes (1998), the number of questions depends on the type of research being performed, the interest of the public with respect to the matter and the form in which the questionnaire will be applied. For Marconi and Lakatos (2009), the questionnaire should not be too long, to avoid fatigue and disinterest, and not too short, to avoid the risk of not providing enough information. The questionnaire must also be accompanied by instructions and explanatory notes for the informant be made aware of what is required of him/her. In the creation of the graphic design the esthetics, ease of handling, space allowed for the answers and arrangement of items in order to facilitate the computation of the data should be observed. For Labes (1998), the esthetics of the questionnaire may influence attracting the attention of the respondent and motivating him/her to complete and return the questionnaire.

With the questionnaire prepared, a preliminary test or (3) pre-test is carried out in a small population outside the target of study before the final application of the questionnaire to improve it and increase its validity (MARCONI AND LAKATOS, 2009). Once the questionnaire has been tested, the following can be performed: (4) its application, delivering it into the hands of the respondents either by e-mail, in person, or online, the choice being dependent on the size of the population, geographical location, resources, time and other facilities (LABES, 1998). The rate of return should be monitored periodically to carry out the collection of data and the subsequent (5) tabulating where the answers are organized in a table according to the subjects and respondents, to enable the statistical calculations to be carried out. The calculation of the answers to each question will allow the researchers to measure quantitatively the information collected and to perform (6) the analysis and interpretation of data by means of the concatenation, structuration and establishment of correlations that allow the researchers to reach clear and objective conclusions regarding the research. The results of the research are usually disseminated in research reports.
STEP 1: PLANNING

Identify the problem and define the objectives, target public and strategies for development.

\section{STEP 2: PREPARATION}

Prepare the content of the questionnaire and create its graphic design.

\section{STEP 3: PRE-TEST}

Perform a preliminary test.

\section{STEP 4: APPLICATION}

Distribute the questionnaire, monitor the rate of return and collect the data.

STEP 5: TABULATING

Tabulate the data.

STEP 6: ANALYSIS AND INTERPRETATION

Analysis of responses and dissemination of results in a report.

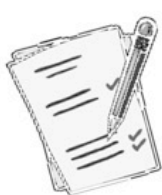

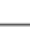

\section{STEP 1: PLANNING \\ Identify the problem and define the objectives, target public and strategies for development. \\ STEP 2: PREPARATION \\ Prepare the content of the questionnaire and create its graphic design. \\ STEP 3: PRE-TEST \\ Perform a preliminary test. \\ STEP 4: APPLICATION return and collect the data. \\ STEP 5: TABULATING \\ Tabulate the data. \\ STEP 6: ANALYSIS AND INTERPRETATION \\ Analysis of responses and \\ dissemination of results in a report.}

Distribute the questionnaire, monitor the rate of

Figure 4. Procedures for the application of the tools in the market layer. Based on:A. Questionnaire: Labes (1998), Brace (2004), Gil (2008), Marconi and Lakatos (2009). B. Bibliographical research: Marconi and Lakatos (2009).

ISSN: 07 I8-2724. (http://www.jotmi.org)

Journal of Technology Management \& Innovation @ Universidad Alberto Hurtado, Facultad de Economía y Negocios. 
The second tool (b), shown in Figure 4 for the survey of the customer priorities, involves bibliographical research in secondary sources, that is, publications, bulletins, newspapers, specialized magazines, books, studies on trends and, especially the Internet. The purpose of this tool according to Marconi and Lakatos (2009) is to place the researcher in direct contact with what has been reported regarding a certain subject. The bibliographical research includes the (I) choice of subjects that will be researched and then proceed to the (2) identification of relevant bibliographical references on the subjects in public libraries, publishers, on the Internet, and in journals, theses, books, magazines and other documents. Having conducted a survey of the documents of interest their (3) localization and (4) compilation are carried out and to finally researchers must, (5) analyze and interpret critically the effective usefulness of the research. According to Marconi and Lakatos (2009), the critique of the document is made both externally (investigating the authenticity and originality) and internally (appreciating the meaning and value of the content).
Continuing the process of Figure 3, in activity (2.2) the current and potential technologies for the product line are analyzed in the pursuit of search technological opportunities that impact the strategic goals of the organization. Some tools that may be used are the S-curve, the technology portfolio matrix, reverse engineering and the bibliographical research detailed in Figure $4 \mathrm{~b}$. In addition to the technological and market opportunities other factors (political, economic, social, environmental and regulatory) are analyzed, which may have an impact on the goals of the organization in a positive or negative way (activity 2.3 ) by means of the bibliographical research.

In activity 2.4 the market layer is filled out with information previously analyzed and the result is evaluated, i.e., what are the opportunities to innovate the product line and what are the threats to be overcome to achieve the goals of organization. At the end of the phase, activity 2.5, the gaps in knowledge and information are registered through of a distinctive sign (e.g. a flag) and the information of doubtful reliability with a question mark for future research and verification (Ibarra, Ogliari and Back, 2008). In the following phase, the scenarios registered in market layer will guide the team in the study of strategic implications.

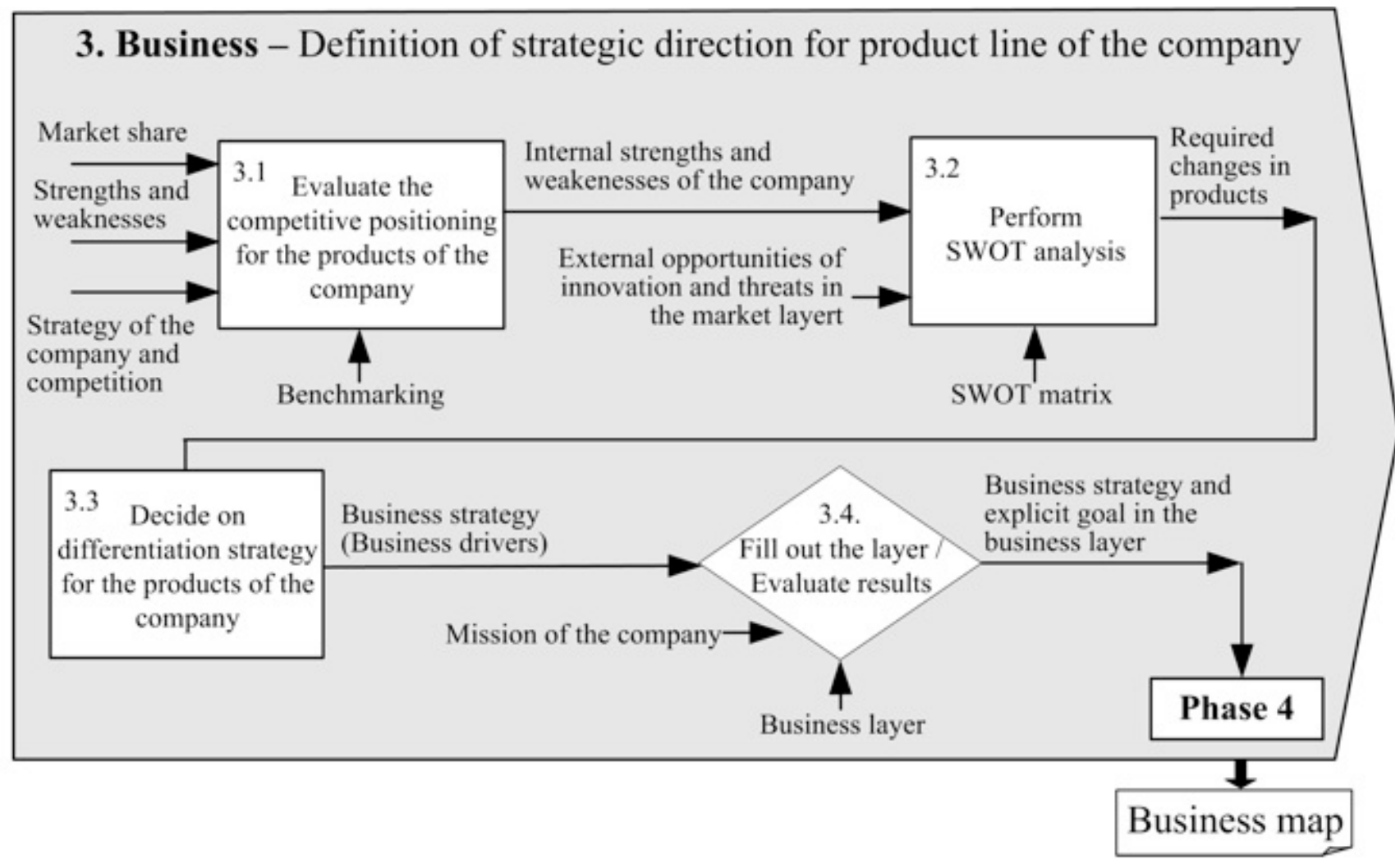

Figure 5. Flow of activities of definition of strategic direction for product line (adapted from Ibarra, Ogliari and Back, 2008).

ISSN: 07 I8-2724. (http://www.jotmi.org)

Journal of Technology Management \& Innovation (c) Universidad Alberto Hurtado, Facultad de Economía y Negocios. 
Definition of strategic direction for product line of the company: business layer

This phase consist in establishing a strategic goal of differentiation for the company's products, based on the scenarios identified in the previous phase and an evaluation of the company's position with regard to competition. The flow of activities is shown in Figure 5.

Firstly, in activity (3.I) the assessment of the competitive positioning for the products of the company with respect to competition is carried out through Benchmarking. This evaluation aims at obtaining information on the internal strengths and weaknesses of the product and, together with the external opportunities and threats (in the market layer), the SWOT analysis (Strengths, Weaknesses, Opportunities and Threats) is performed (activity 3.2). This analysis is performed following the steps of Figure 6, using the SWOT matrix as a tool.

After $(I)$ listing the internal and external factors in the quadrants of the SWOT matrix, (2) a correlation analysis of variables as 0 (zero) - non-existent; I (one) - weak; 3 (three) - medium; 9 (nine) - strong correlation is performed. Based on the results of this correlation an individual score for each aspect is obtained which allows us to (3) prioritize the most important items to provide support in order to (4) define strategies to compete in the market. Figure 7 illustrates how this process of analysis and prioritization of the variables is carried out in the SWOT matrix, based on the criterion and consensus of the team involved.

In Figure 7 the example is considered in which a strong point is the competence of the employees, registered in quadrant $\mathrm{I}$, assuming that an opportunity of rapid growth of the market was registered. To analyze the relationship between the two variables it is verified whether the strong point has a non-existent [0], weak [I], medium [3] or strong [9] relationship with the opportunity. In this case, it is more likely that there is a strong relationship between the 'competence of staff' and the 'rapid growth of the market', and this relationship can be given a value of nine [9]. Likewise, the relationship between 'competence of staff' (strength) and 'increasing regulation' (threat) registered in quadrant II could be assessed, with a non-existent relationship being established and a value of zero [0] given.

This analysis of the relationship is concluded by filling in all of the cells in the matrix. At the end, the sum of each variable per quadrant is obtained (i.e. 15 and 13 for the strong point of competence of staff). With the objective of prioritizing the most significant factors for the company's performance, in order to define strategies, an indication of importance is determined. To this end, the values related to the strengths (that take advantage of the opportunities and protect against threats) are summed and subtracted from those related to the weaknesses (which impede to seizing of the opportunity and leave the company more susceptible to threats). In the case of Figure 7, the importance obtained from the first strong point of competence of staff is 28 , while the opportunity of market growth was affected by weaknesses obtaining a value of 2 . Thus, strategies can be defined that reinforce the main strengths and weaknesses in order to to take advantage of opportunities and avoid the threats. Based on the SWOT analysis, in activity (3.3) the team must decide the strategy for the product differentiation with respect to its competitors, in order to gain a competitive advantage. In activity (3.4) the information analyzed is positioned in the business layer and the results obtained are analyzed, i.e., the goal and the strategic actions to be followed by the company to achieve its goals. In this way, the company builds up a visual and common representation of the strategic context of the sector of activity and the goals and plans to achieve its goals for decision making, communication and

\section{STEP 1: LIST OF FACTORS}

List the external factors (opportunities and threats) and internal factors (strengths and weknesses) in the SWOT matrix.

\section{STEP 2: ANALYSIS OF CORRELATION}

Correlate external and internal factors in the SWOT matrix.

\section{STEP 3: PRIORITIZATION OF FACTORS}

Determine the most important factors of the company's situation.

\section{STEP 4: DEFINITION OF STRATEGIES \\ Define the strategic directions to \\ be followed by the company.}

Figure 6. Procedure for the development of SWOT matrix in the business layer. Based on: Lee and Ko (2000), Weihrich (2002).

ISSN: 07 I8-2724. (http://www.jotmi.org)

Journal of Technology Management \& Innovation @ Universidad Alberto Hurtado, Facultad de Economía y Negocios. 
dissemination. The business layer directs the construction of the other layers in order to formulate the strategies of products and technologies consistent with the objective of the company.

\section{Research methodology}

The object of the research is the empirical analysis of the detailed tools in Figures 4 and 6 of market layer - questionnaire for consultation with the consumers and bibliographical research - and the business layer - SWOT matrix, being characterized as qualitative research. The qualitative research was applied and developed applying the method of case study. The strategies adopted in the research as Gil (2002) are both exploratory - in order to understand the problem and have greater familiarity to make it explicit - and descriptive - seeking to describe the characteristics of the applicability of tools systematized within a given context.

The case study is a type of research that consists of the deep and comprehensive study of one of a few cases, in a manner that allows extensive and detailed knowledge to be gained. To minimize the effect of bias, which compromises the quality of the results, it is recommended that the researcher to puts considerable effort into the planning, collection and analysis of data (GIL, 2002).
In the planning of the case study a (I) small Colombian company acting in the clothing sector that seeks access to the Brazilian market is considered. This unique case was used to ascertain the possibility for access and to have a initial experience that provides the focus for the definition of the parameters that allow the researcher to proceed to a larger number of cases. The procedure of the collection of data for the construction of the roadmap and the respective sources of research is inherent to the purpose of each tool applied.According to Gil (2002), obtaining data through various procedures, using multiple sources of research, is crucial to obtaining significant results. The results of the application of the tools will be analyzed empirically - through observation and experience - according to the complexity, time and cost of implementation as well as the relevance and quality of the resulting information for the construction of the roadmap, and these criteria most hinder the application of the method according previous experiences. The attendance of each criterion will be verified according to the levels of low, medium and high.

\section{Case study}

The case study considers a clothing company in Colombia which seeks access to the Brazilian international market.

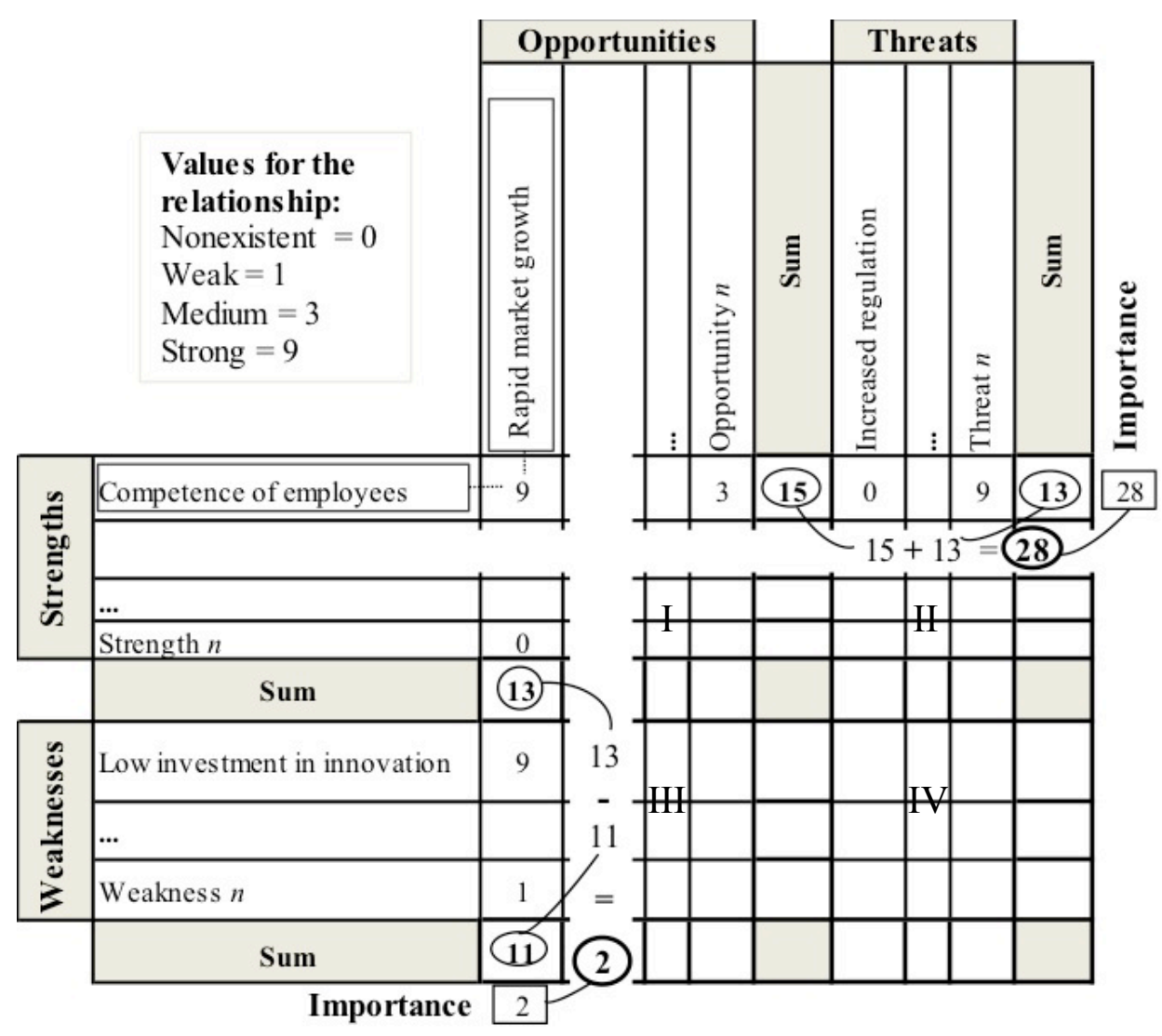

Figure 7. Illustration of the process of analysis and prioritization in the SWOT matrix.

ISSN: 07 I8-2724. (http://www.jotmi.org)

Journal of Technology Management \& Innovation (c) Universidad Alberto Hurtado, Facultad de Economía y Negocios. 
Through the technology roadmapping, the company aims to build knowledge on the intended market as it stands at present and its future direction, seeking to identify potential opportunities to prioritize strategic actions that reduce the uncertainties and risks of access to a new market. Without this knowledge, the company could fail upon entering into a field without knowledge of the competitive environment and its competitors.

In this study the most representative product line of the company: feminine sleepwear. Considering that the life cycle of such products in the clothing sector changes quickly depending on the seasons of the year, the time scale of the roadmap is I year, being subdivided into: spring/summer and autumn/winter. The mapping team was composed by the general manager and the marketing assistant of the clothing company, both with commercial and technical expertise. And, the authors of this article took on the role of facilitators of the technology roadmapping process.

Identification of future opportunities and threats for product innovation: market layer

The first activity of this phase (2.I) consists of the identification of the needs of consumers. For this purpose the questionnaire illustrated in the Appendix was developed, following the procedure shown in Figure 4a. In step (I) of the planning, firstly the problem that will be resolved with the research was identified, being in this case the "consumption profile of Brazilian women regarding sleepwear". The specific objectives of the research were then defined by the manager of the company, which were listed and grouped according to the type of information to be obtained in order to guide the formulation of the questions in an organized way and the subdivision of the roadmap into layers (Table I). The target audience of the research was then defined. According to Boynton and Greenhalgh (2004), the selection of a sample group is given by: $i$ ) the availability of participants at the time of the study (by chance); ii) sampling (random) in a simple, systematic and stratified way; iii) subsection (limited) of a group; iv) the traits within a population (e.g. social class, age or gender) when seeking representativeness of a large population; and $v$ ) indication by other people for groups difficult to approach. In this study, the sample was selected on the basis of socioeconomic status and the availability of participants in the analysis, being "middle-class Brazilian women between 13 and 44 years of age from different parts of Brazil who live in the South Region near the industrial center of clothing production".

To finalize the planning of the questionnaire, strategies for later actions were defined, such as the invitation to participate and the collection and analysis of data. Thus, it was defined that the questionnaire would be developed and implemented via the Internet through sites such as http:// questionpro.com/ and http://pt.surveymonkey.com/, seeking to facilitate the development of the art graphics, the implementation, the monitoring and the tabulation of data. The questionnaire would then be sent by e-mail explaining the object of research and ensuring the privacy of data. The most relevant information would be finally positioned in the market layer of the technology roadmap.

In the second step (2) of preparation, the questionnaire questions were written on paper following the guidelines proposed by Brace (2004), Boynton and Greenhalgh (2004)

\begin{tabular}{|c|c|}
\hline \multicolumn{2}{|r|}{ Problem: Consumer profile of Brazilian women regarding sleepwear } \\
\hline $\begin{array}{r}\text { Types of } \\
\text { information }\end{array}$ & Objectives of the questionnaire \\
\hline \multirow{5}{*}{$\begin{array}{r}\text { Attributes of } \\
\text { preference }\end{array}$} & What are the factors that influence the purchase and their order of importance? \\
\hline & What is the frequency of purchase and the average amount paid for sleepwear? \\
\hline & $\begin{array}{l}\text { Is there a need for homewear / loungewear? What is the price expectation in relation to } \\
\text { this type of clothing? }\end{array}$ \\
\hline & What is the dressing style of the consumer? \\
\hline & $\begin{array}{l}\text { Does the consumer consider the brand at the time of purchase? What would be the } \\
\text { ideal sleepwear? }\end{array}$ \\
\hline Garment & What are the preferences in relation to type of garments, the details and the fabric? \\
\hline $\begin{array}{r}\text { Uses in } \\
\text { everyday life }\end{array}$ & What habits are associated with the use of sleepwear? \\
\hline
\end{tabular}

Table I. Grouping of the questionnaire objectives for the clothing company

ISSN: 07I 8-2724. (http://www.jotmi.org)

Journal of Technology Management \& Innovation @ Universidad Alberto Hurtado, Facultad de Economía y Negocios. 
and Gil (2006). The online graphic design of the questionnaire was then configured in the desired format and the question type and order, as well as the deadline for processing the results of the research, were determined. In the third step (3) the online questionnaire was submitted to a pre-test with three participants with the same characteristics as the intended audience, seeking to validate the clarity, the ease with which the questions can be answered, the ease of understanding, the font size, the visual appearance, the filling in time and the generation of consistent responses, among others.

The fourth step (4) involved the application of the questionnaire. It was distributed to the audience by e-mail, inviting them to use the link to access the online questionnaire. A period of one month was given to allow the respondents to answer at a time they found appropriate, and the number of respondents was periodically monitored on the website. Proceeding to the fifth step (5) of tabulating the data, the website used assisted in processing the closed responses provided by the participants, while the open-ended responses were tabulated by the researchers through association by similarity. Finally, (6) the analysis and interpretation of the responses was carried out.

Figure 8 illustrates how the information derived from the questionnaire was positioned in the market layer on the roadmap in order of importance with the key customer feedback added using the symbols defined in the legend.
As a result of this study, it was observed that the questionnaire for consumers was easy to apply because of the use of an online system which allowed the graphic design to be carried out and to make the questionnaire available to the target audience. On average, the respondents took 8 minutes to answer the questionnaire according to the calculation of the online system. Time was not spent in the preparation, monitoring of the rate of return or the final tabulating of the results, since these tasks were automatically performed by the online system for the majority of the questions. The activity that involved the greatest amount of time was the formulation of questions in the questionnaire providing them in an appropriate language and a convenient format and sequence for the subsequent tabulating of data. In general, the time required for the preparation, application, tabulating and analysis of the questionnaire was relatively low, approximately 15 days. It is assumed that the rate of return of the questionnaire of $33.33 \%$ (of 120 invited, 40 responded) can be attributed to the lack of access to the Internet of the target audience during the period of the survey, to the perceived risk of Internet viruses or to lack of knowledge on filling out online questionnaires.

On the other hand, the questionnaire applied did not involve high costs of application due to the use of a free online system for conducting surveys. Sophisticated systems, however, can associate a cost of acquisition or development. The results obtained from the application of the questionnaire also provided information relevant to the technology

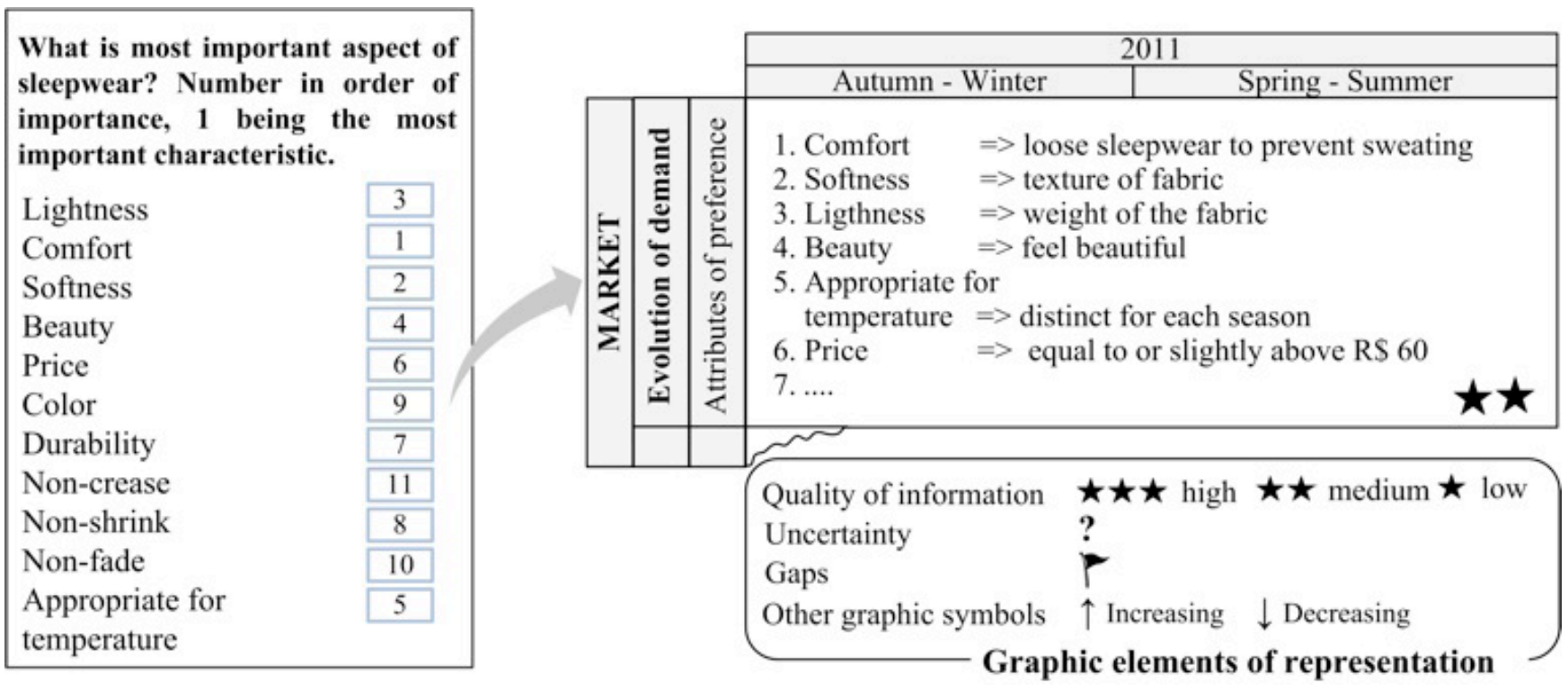

Figure 8. Illustration of the positioning of information obtained from the questionnaire on the technology roadmap for the product line of feminine sleepwear

ISSN: 07 I8-2724. (http://www.jotmi.org) 
roadmap, guiding the planning of new products according to customer's preferences as illustrated in Figure 8. However, due to possible uncertainties involved in the responses of the respondents, the quality of the information obtained was considered medium as represented in Figure 8 through the number of stars indicating the quality of information.

In addition to the application of the questionnaire, bibliographical research was carried out to identify market and technology trends as well as social, environmental, political and economic trends that affect the clothing sector. In this regard, the steps presented above in Figure $4 \mathrm{~b}$ were implemented. Firstly, (I) the subjects of the research were chosen within the main categories of the market layer related to the evolution of market demand, the evolution of technology available for products and other trends. The resulting
14 subjects were classified by categories of information to facilitate its collection and positioning in the market layer. The possible sources of research for the subjects were then identified as shown in Table 2. Note that the sources are mostly online because information related to the clothing sector is usually disseminated on the Internet.

For the (2) identification of bibliographical references the factors considered were the reliability of the source, quality and ease of access to the researched information. The bibliographical references were thus (3) localized and then (4) compiled into the digital media classified into the categories of information presented in Table 2. With the information gathered, (5) critical analysis and interpretation were carried out to evaluate the effective usefulness for the purposes of the market layer.

\begin{tabular}{|c|c|c|}
\hline $\begin{array}{r}\text { Categories } \\
\text { of information }\end{array}$ & Subjects to be researched & $\begin{array}{r}\text { Types of } \\
\text { research sources }\end{array}$ \\
\hline \multicolumn{3}{|c|}{ Evolution of market demand } \\
\hline $\begin{array}{r}\text { Competi- } \\
\text { tors }\end{array}$ & $\begin{array}{l}\text { 1. What are the solutions offered by major competitors and their advantages? } \\
\text { 2. What are the innovations introduced in the clothing industry? Are new } \\
\text { models being provided? }\end{array}$ & $\begin{array}{r}\text { Sites and } \\
\text { news of compet- } \\
\text { itors }\end{array}$ \\
\hline $\begin{array}{r}\text { Fashion } \\
\text { trends }\end{array}$ & $\begin{array}{l}\text { 3. What are the trends in colors, prints and consumption for future collec- } \\
\text { tions? }\end{array}$ & $\begin{array}{r}\text { Fashion } \\
\text { sites }\end{array}$ \\
\hline $\begin{array}{r}\text { Expected } \\
\text { growth }\end{array}$ & $\begin{array}{l}\text { 4. What is the forecast for consumption and investment in the sleepwear } \\
\text { market? } \\
\text { 5. What are the niches of the market? } \\
\text { 6. What is the potential for the emergence of substitutes? }\end{array}$ & $\begin{array}{r}\text { Studies } \\
\text { of trends in the } \\
\text { clothing industry }\end{array}$ \\
\hline \multicolumn{3}{|c|}{ Other trends } \\
\hline Social & 7. What are the cultural and behavioral changes in relation to sleepwear? & \multirow{2}{*}{$\begin{array}{r}\text { Studies of } \\
\text { trends }\end{array}$} \\
\hline $\begin{array}{r}\text { Environ- } \\
\text { mental } \\
\end{array}$ & 8. What are the trends in environmental terms in the product life cycle? & \\
\hline Political & $\begin{array}{l}\text { 9. What are the trade agreements for importation to Brazil and other stan- } \\
\text { dards that must be met? }\end{array}$ & \multirow{2}{*}{$\begin{array}{r}\text { Proexport } \\
\text { Colombia and } \\
\mathrm{MRE}^{1}\end{array}$} \\
\hline Economics & 10. What are the costs of importation to Brazil? & \\
\hline & Evolution of technological offer & \\
\hline
\end{tabular}

11. What are the main suppliers of fabrics? What drives the adoption of one or another supplier? What is added to the products commercialized by the company?

Fabrics 12. What are the fabrics offered by the textile market and their characteristics and advantages?

Sites of textile companies and of innovation

13. What are the new technologies in fabrics according to the leading authorities on the subject?

Processes

14. What are the main practices of process management related to the life cycle of sleepwear (in manufacturing, cutting, sewing and finishing)?

Table 2. Subjects and sources to be researched in the clothing sector.

'Ministry of external relations of Brazil (MRE). ${ }^{2}$ Brazilian association of textile and clothing industry (ABIT)

ISSN: 07 I8-2724. (http://www.jotmi.org)

Journal of Technology Management \& Innovation (c) Universidad Alberto Hurtado, Facultad de Economía y Negocios. 
Figure 9 illustrates how the relevant information of the different sources was analyzed and positioned in the market layer of the technology roadmap.

To facilitate the visualization of the roadmap, the information on the trend was summarized in a sentence using graphic symbols illustrated in the legend of Figure 9. At the end of each piece of information the quality of the information (high, medium or low), depending on its source, was indicated through starts. Considering that in the bibliographical research preference was given to recognized sources in the clothing sector, the quality of information in the example in Figure 9 was considered high $(* * *)$. Likewise, the other information on the clothing sector, in particular sleepwear, was analyzed and positioned. Dubious information was marked on the roadmap with a question mark for monitoring and verification of the veracity and pertinence to the company. Similarly, gaps in information, i.e. the spaces of the roadmap indicating that information was not founded, were highlighted though a flag to indicate that monitoring and follow-up is required.

In general, the process of bibliographical research was facilitated and accelerated by the use of the Internet, the relevant material being quickly located and compiled. On average the time spent by two people working together on the identification, location and compilation of material was 3 days. However, the time spent on the last activity of analysis and interpretation of the bibliographical references found was longer ( 15 days) because of the reading and filtering of the most important data for the elaboration of the roadmap. The cost of the implementation of the bibliographical research was low due to the availability of information on the Internet. However, it is important to consider that the search for more detailed information could involve costs for acquisition, for example, hiring expert consultants in the area. Regarding the relevance, it can be assumed that the information obtained was important since it came from recognized sources of the sector. For this same reason, the vast majority of the information was considered to be of high quality.

With the information gathered through the questionnaire and the bibliographical research the market layer was developed for the feminine sleepwear. Based on this information, it was possible to determine the opportunities and threats to the access of the company to the Brazilian sleepwear market (Table 3), which served as a basis to perform the SWOT analysis in the next step.

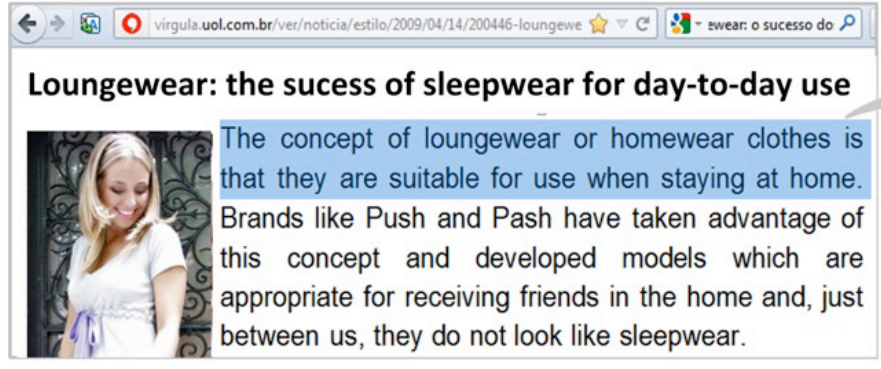

Figure 9. Example of positioning of information obtained by bibliographical research in the market layer of the technology roadmap for the product line of feminine sleepwear

\begin{tabular}{|ll|}
\hline & External environment \\
\hline & $\cdot$ New market niches: pregnancy and post-surgery \\
\hline Opportunities & $\cdot$ Increased need for homewear \\
& $\cdot$ Growth potential of Brazilian clothing sector \\
& $\cdot \ldots$ \\
\hline & $\cdot$ High number of competitors \\
& $\cdot$ Trend toward eco-friendly products \\
\hline Threats & $\cdot$ Economic barriers to market entry \\
& $\cdot \ldots$ \\
& \\
\hline
\end{tabular}

Table 3. Major opportunities and threats for offering feminine sleepwear on the Brazilian market

ISSN: 07 I8-2724. (http://www.jotmi.org)

Journal of Technology Management \& Innovation @ Universidad Alberto Hurtado, Facultad de Economía y Negocios. 
Continuing with the process of technology roadmapping, the following shows the analysis and definition of the strategic plan for the feminine sleepwear line of the company.

\section{Definition of strategic direction for product line of the company: business layer}

This phase starts with the assessment of the competitive positioning of the sleepwear of the company in relation to that of its competitors by means of Brainstorming among the authors of this article. To this end, the criteria in Table 4 related to the product life cycle were analyzed, from the purchase of materials, production, distribution and marketing through to the use and deactivation / disposal of the product. Through a positive sign (+) and negative (-) the strengths and weaknesses for the products of the company were evaluated as shown in Table 5.

The SWOT analysis was then performed. For this, the strengths and weaknesses previously determined were (I) listed in the rows and columns of the SWOT matrix together with the opportunities and threats identified in the market layer. The next step was to (2) analyze the degree of relationship - non-existent [0], weak [1], medium [3] or strong [9] of one variable in relation to another, exploring each individual node of the matrix (Figure 10).

In each of the quadrants, the following subjects were examined respectively: i) to what degree of intensity does each strength help the organization to take every opportunity?; ii) to what degree of intensity does each strength helps the organization to neutralize or mitigate each threat?; iii) to what degree of intensity does each weakness make it difficult to take every opportunity?; and iv) to what degree of intensity does each weakness potentiate the effects of each threat to on the company?.

In Figure 10 (see next page) it can be seen that in the evaluation of the team the degree to which the relationship of suppliers (strength) helps the organization to fill the new market niches identified (opportunity) was considered to be average, with a value of three. This is because, according to the analysis, the suppliers help with inputs to satisfy the new markets, but the company is not totally dependent on

\begin{tabular}{|c|c|c|c|c|}
\hline \multirow{2}{*}{ Criteria } & \multirow{2}{*}{ Company } & \multicolumn{3}{|c|}{ Competitors } \\
\hline & & $\mathbf{A}$ & B & $\mathbf{C}$ \\
\hline \multirow{2}{*}{ Purchase of materials } & Relationship with suppliers (+) & Unknown & Unknown & Unknown \\
\hline & Ecological fabrics (-) & Yes & No & No \\
\hline \multirow[t]{3}{*}{ Production } & Capacity $(+)$ & Unknown & Unknown & Unknown \\
\hline & Mix of products $(+)$ & No & No & No \\
\hline & Modeling (-) & Yes & Yes & Yes \\
\hline Selling & Experience (-) & High & High & High \\
\hline$\ldots$ & $\ldots$ & .. & . & \\
\hline
\end{tabular}

Strength (+) / Weakness (-)

Table 4. Evaluation of feminine sleepwear of the company versus competitors

\begin{tabular}{|c|c|}
\hline & Internal environment \\
\hline Strengths & $\begin{array}{l}\text { Relationship with suppliers } \\
\text { - Diversification of sleepwear (including homewear) } \\
\text {. Capacity of production } \\
\quad \ldots\end{array}$ \\
\hline Weaknesses & $\begin{array}{l}\text { Lack of experience in selling the product on the market } \\
\text { Lack of use of eco-friendly fabrics } \\
\text {. Difference in physical type of consumer } \\
\text {. ... }\end{array}$ \\
\hline
\end{tabular}

Table 5. Major strengths and weaknesses for the feminine sleepwear of the company

ISSN: 07I 8-2724. (http://www.jotmi.org)

Journal of Technology Management \& Innovation (C) Universidad Alberto Hurtado, Facultad de Economía y Negocios. 
them to take full advantage of the new markets. The same procedure of analysis was performed for all of all the cells of the SWOT matrix, obtaining at the end a total sum for each variable of the quadrants. An example is the strength of diversification of the company's products, which had a total value of $3 \mathrm{I}$ in relation to the extent to which they take opportunities and a value of 9 for the neutralization of threats.
The total value obtained thus allows the determination of the importance of each item on the external lines of the matrix in order to (3) prioritize the most significant factors in terms of the company's performance to aid the strategic decision making. The values related to the strengths that enable the achievement of the goals were summed (in the case of the strength of diversification of products this resulted

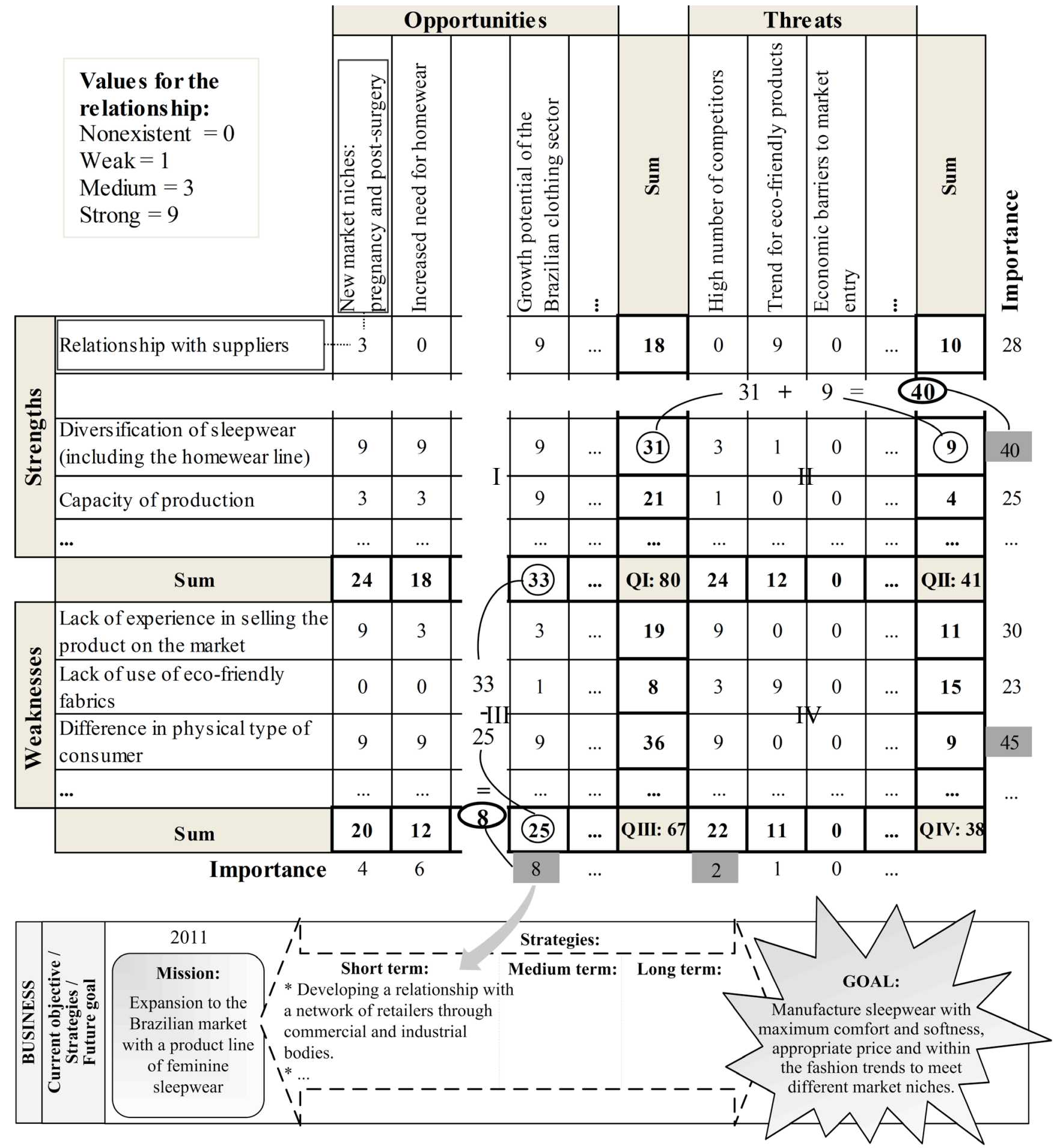

Figure 10. Example of positioning of information obtained in the SWOT matrix in the business layer of the technology roadmap for the ISSN: 07I 8-2724. (http://www.jotmi.org) Journal of Technology Management \& Innovation (c) Universidad Alberto Hurtado, Facultad de Economía y Negocios. 
in an importance of $31+9=40$ ). The values related to the weaknesses that hinder the achievement of the opportunities and enhance the threats were subtracted. The opportunity for the growth of the Brazilian clothing sector, for example, resulted with an importance of 8 considering the weaknesses of the company.

At the end, the items with the highest scores guided the (4) definition of strategies to be followed by the company in the business layer. For example, in the case of opportunities, the most concrete example to be seized is precisely the growth of the Brazilian clothing sector (score 8). Based on this opportunity it can be seen in Figure 10, that a short-term strategy was defined in the business layer of "developing the relationship network of retailers through commercial and industrial bodies of Brazil". Considering the most important aspects of the SWOT analysis strategies of short, medium and long term were defined for the company to attain its current mission and desire of "expansion to the Brazilian market with the product line of feminine sleepwear" to achieve the future goal defined with the market information. The analysis of the correlations between the items of the SWOT matrix was found to be complex in terms of the debate generated regarding the relationships between the variables of each quadrant, which required considerable time (6 hours of discussion) to be completely carried out. However, this time can vary according to the number of decision makers and items being analyzed. The cost of the implementation of SWOT matrix was low due to the operationalization of this tool by the team using low-cost worksheets. On the other hand, the results obtained with the application of the SWOT matrix were relevant since they highlighted the most important aspects that must be focused on by the company to compete strategically in the market. It is assumed that without the application of the SWOT matrix, the factors perceived as important by the team could have been different. Finally, considering that the SWOT analysis involved the subjective analysis of the team, the quality of information was considered medium.

Table 6 summarizes the empirical analysis of the tools to support the technology roadmapping by the authors based on the criteria of complexity, time, cost, relevance and quality and classified as high, medium or low.

As can be seen, the tools of the market layer, that is, the questionnaire and bibliographical research were found to be easier to implement than the SWOT analysis tool of the business layer. With respect to the time invested, the application of the questionnaire took less time because of the use of the online system which facilitated the graphic design, preparation, monitoring and tabulating of data. In general, all the tools involved low cost implementation with quality results being obtained which were relevant to the development of the technology roadmap. This, it is expected to provide support to the mapping team in the planning of the use of tools for the realization of the roadmap.

\section{Final considerations}

This article presented an analysis of the tools used in the technology roadmapping through their application to the clothing sector. By means of their application, it was possible to understand how the tools oriented toward the market and business layers of the technology roadmap work, i.e. if they are complex or easy to apply, quick or time consuming, cheap or expensive and if they bring quality information and relevant to the technology roadmapping in order to contribute by aiding the implementation of the method.

\begin{tabular}{|c|c|c|c|c|c|}
\hline \multirow[b]{2}{*}{ TOOLS } & \multicolumn{5}{|c|}{ CRITERIA } \\
\hline & Complexity & Time & Cost & Relevance & Quality \\
\hline \multicolumn{6}{|l|}{ Market layer } \\
\hline Questionnaire (online) & Low & Low & Low & High & Medium \\
\hline Bibliographical research & Low & High & Low & High & High \\
\hline \multicolumn{6}{|l|}{ Business layer } \\
\hline SWOT matrix & High & High & Low & High & Medium \\
\hline
\end{tabular}

Table 6. Comparative results from the analysis of support tools for technology roadmapping

ISSN: 07 I8-2724. (http://www.jotmi.org) 
Regarding the tools of the market layer, the most used approaches of a questionnaire and bibliographical research were analyzed, assisting in the identification and analysis of information that constitute opportunities or threats to the company. The questionnaire applied through online resources made the process easier, faster and cheaper, obtaining quality information which was relevant in relation to the customer preferences in a market that is beginning to be explored by the company. In the same way, the bibliographical research through online sources recognized in the industry facilitated the search for information at low cost and provided important information of high quality. However, the analysis and interpretation of bibliographical references found increased the time spent in the process.

Moreover, the SWOT analysis tool of the business layer became complex and took a long time in terms of the relationships analyzed in the matrix during the application. Nevertheless, the cost involved in the electronic operationalization was low and the results, being of good quality and relevant, were able to support the process of defining strategies for the company to achieve its future goal.

The use of three tools was appropriate for the company according to the manager in terms of the structuring of the most important information regarding opportunities and threats associated with the intended market in a time horizon and provided support in the decision making that reduced risks and directed the company strategically. Through applying the technology roadmapping in the case study, the manager perceived that the competitive intelligence in the market layer has great interaction with the strategic planning of the business layer, one process feeding the other dynamically and continuously. Thus, the definition of strategies in the business layer must be improved with new information in the market layer making it possible to place the company on a new level of competitiveness.

With the results of this application, it is expected conditions could be created to enable the application of the method of technology roadmapping in companies, especially SMEs, whose managers are unaware of its implementation or have constrained resources. In the case study, the simplicity and usefulness of the tools analyzed in relation to others that may be more complex, expensive and take a long time to implement was demonstrated. It is also expected that this work will motivate new studies on the application of other methods and tools such as reverse engineering, bionics, scenario analysis, among others, pointing out the benefits and difficulties in their application as a focus of future research.

\section{Acknowledgments}

The authors would like to thank to Sergio Enrique I. Martínez, manager of the clothing company, for his availability and collaboration in the execution of this work.

\section{References}

ALBRIGHT, R., Kappel,T. (2003). Roadmapping in the corporation. Research Technology Management, 42(2), 3 I-40. doi: I0.1 I09/EMR.2003.24903.

BOYNTON, M., Greenhalgh, T. (2004). Selecting, designing and developing your questionnaire. BMJ. 328, $1312-1315$. doi: $10.1|36 / b m j .328 .745| .13 \mid 2$.

BRACE, I. (2004). Questionnaire design: how to plan, structure and write survey material for effective market research. Kogan Page, London. 289 p. doi: I0.5860/CHOICE.42-3520.

CORAL, E., Ogliari, A., Abreu, A. (2008). Gestão integrada da inovação: estratégia, organização e desenvolvimento de produto, primeira edição. Editora Atlas, São Paulo.

GIL,A.C. (2002). Como elaborar projetos de pesquisa, quarta edição. Editora Atlas, São Paulo.

GIL,A.C. (2006). Métodos e técnicas de pesquisa social, sexta edição. Editora Atlas, São Paulo.

GROENVELD, P. (1997). Roadmapping integrates business and technology. Research Technology Management. 40(5), 48-55.

GROSSMAN, D.S. (2004). Putting technology on the road. Research Technology Management. 47(2), 4I-46.

IBARRA, C.J. (2007). Sistematização do processo de mapeamento tecnológico de produtos. Dissertação (Mestrado em Engenharia Mecânica) - Programa de Pós Graduação em Engenharia Mecânica. Florianópolis: Universidade Federal de Santa Catarina.

IBARRA, C.J., Ogliari, A., Back, N. (2008). Systematization of technology roadmapping. Product Management \& Development. 6(2), | $-2 \mid$.

IBARRA, C.J., Ogliari,A., Back, N. (2009). Uso do mapeamento tecnológico no desenvolvimento de produtos: enfoque na camada produto e tecnologia. In Congresso Brasileiro de Gestão de Desenvolvimento de Produto, CBGDP 2009. São José dos Campos, SP, Brasil. 
MARCONI, M.de A., Lakatos, E.V. (2009). Fundamentos de metodologia científica, sexta edição. Editora Atlas, São Paulo. $315 \mathrm{p}$.

MCCARTHY, R.C. (2003). Linking technological change to business needs. Research Technology Management. 46(2), 47-52. doi: 10.1 109/EMR.2003.24905.

MCMILLAN, A. (2003). Roadmapping: agent of change. Research Technology Management. 46 (2), 40-47.

LABES, E.M. (1998). Questionário: do planejamento à aplicação na pesquisa. Editora Grifos, II 5 p.

LEE, S.F., Ko, A.S. (2000). Building balanced scorecard with SWOT analysis, and implementing "Sun Tzu's The Art of Business Management Strategies" on QFD methodology. Managerial Auditing Journal. 15(I/2), p. 68-76. doi: I0.II08/026869000I0304669.

PHAAL, R., Farrukh, C., Probert, D. (200I). T-Plan: the fast start to Technology Roadmapping - planning your route to success, University of Cambridge. Institute of Manufacturing, Great Britain, UK.

RICHEY,J.M., Grinnell, M., 2004. Evolution of roadmapping at Motorola. Research Technology Management. 47(2), 37-4I.

WEIHRICH, H., 2002. The TOWS Matrix: a tool for situational analysis. Long Range Planning, I-19. doi: 0024630I/82/020054-I3S03.00/0. 